glands are non-adherent, they can be enucleated with great ease. On the 8 th of this month, through an incision an inch and three-quarters long, I removed eight glands, three as large as walnuts, and all of them caseous. Seven days after, the wound was healed, and the scar even then scarcely noticeable. But when the tubercular process has been allowed to run its course for a long time, and adhesions have formed, then the real difficulty is experienced, and often a tedious dissection is raquired before the diseased glands can be removed. And here let me say that this difficulty is often of our own making. We meet a case in which two or three glands in the neck are swollen and hard. A careful inquiry into the history of the case will satisfy us that the glands are scrofulous. But instead of dealing with them at once, we allow the disease to spread, more glands to become infected, and adhesions to form, whilst we wait. Wait for what? To try the effects of this or that external application, painting with iodine, or a host of other remedies, which experience should have taught us in that stage are no remedies at all. Sometimes the delay is due to our unwillingness ธo make a cut which may leave a scar, and then nature takes the matter in hand, the gland softens, an abscess forms, and the end of it is that a far worse scar is left than would have resulted from timely intervention. Besides, all this time other glands are preparing to go through the same process. Such things ought not to be. What I maintain is, that the earlier we attack these glands the less we shall have to do, and the smaller and more insignificant the scar will be; and, what is more important still, the focus of the disease may be got rid of through quite a small opening. Often, however, we have at least this satisfaction, that we cannot blame ourselves if the disease has become extensive. It may be so when first we see the patient, but even in the most extensive cases of scrofulous glands we may hope for a cure by surgical art. I have notes of fifteen patients from whom $I$ excised tuberculous glands. Two were operated on twice and two three times, making in all twenty-one operations. Some of these were comparatively simple cases, two or three glands only requiring removal. Some of the cases were most extensive, and of these three present points of special interest.

The first case was that of a boy aged seventeen, whose neck was enormously swollen on the right side, owing to the enlargement of the glandulæ concatinatæ and submaxillary glands. I operated on him twice. The first time was on June 12th, 1883. A curved incision, about four inches long, was maảe behind the sterno-mastoid muscle, and all the enlarged glands removed. They were all caseous, several presenting centres of suppuration in the middle of the cheesy masses. I mention his case because he was attacked with erysipelas three days after operation. The erysipelas began low down on his back, spread gradually over his whole body, with the exception of the parts underneath the antiseptic dressings. This part remained healthy throughout, and the wound healed well. Some months after I removed the submaxillary glands. A similar mishap occurred in a second case, but both made perfect recoveries.

The second case $I$ wish to mention was that of a married woman, aged twenty-three, who presented a long chain of glands extending from behind the left ear to the clavicle. They were movable and hard in the upper two-thirds, but below they were soft and suppurating. I excised them all at one operation on April 3rd, 1834. The abscess cavity was scraped out, and a drainage-tube inserted through a counter opening close to the clavicle, the wound being itself completely closed. The dressings were not disturbed till the seventh day, when the wound was quite healed. The drainage-tube was removed, and the sinus was completely healed on the fifteenth day. She left hospital three days later. I saw her again a few months ago, a year and three quarters after operation. There were no more enlarged glands, and the incision was reduced to a fine white pliant scar.

The last case to which I shall refer is that of a girl aged eighteen, who was studying to become a schoolmistress, but was rejected on the ground of health, as the left side of her neck was bulged out with a large number of swollen glands. She was greatly disfigured. I operated on the 29th of April, 1884. The incision reached from the mastoid process to within an inch of the clavicle. All the superficial and deep glands were involved, those lying underneath the sterno-mastoid muscle being very difficult to enucleate. I removed in all forty-eight glands at this operation. She made a slow recovery, but a good one. I saw her the other day, nearly two years after operation. There is a long scar, but it is soft, white, and flexible; and she can so arrange her hair as to make it almost imperceptible. She is in excellent health, and has had no return of the disease ; in fact, as we might expect, it is not possible to feel any glands in that side of the neck. I mention this case especially as showing that excision can be safely done, even in such an extreme case.

Before concluding this paper, there is an objection which I should like to answer-an objection which I have heard raised, especially in regard to these extensive operations; and it is this: Is it not a very serious matter to interfere to any great extent with the lymphatic system in the neck? That objection is entirely theoretical ; I have not seen in any of the cases on which $I$ have operated any evil consequence referable to this cause. Besides, we must bear in mind that caseous glands are, to all intents and purposes, functionally destroyed. If there is any reason in the objection at all, the blame must be left at the door, in the firstinstance, of the tuburcular affection; and, secondly, at the door of those, be they doctors or patients, who allow the disease to progress to such an extent-a disease which, I trust, I have shown can be arrested in its early stages by the timely and judicious intervention of surgical art.

\section{NOTES ON A CASE OF EXTRA-UTERINE ABDOMINAL PREGNANCY.}

BY T. W. J. ALLEN, L.R.C.P. LOND., \&e., HONORARY SURGEON TO THE GRIMSEY AND DISTRICT HOSPITAL.

Mrs. - - a aged thirty, fisherman's wife, consulted me on June 27th, 1885. She was of slight build, emaciated, and anæmic-looking. Had been twice married; ten years to second husband. Had two children by first husband, the second eleven years ago. For the last three or four years she had menstruated irregularly, sometimes missing three or four months, and last menstruated about Christmas, 1884. Since the end of February, 1885, she had been suffering from violent pains in the abdomen and back, with flatulence, morning retching, and vomiting. She had been attended for two months previously to seeing me for chronic inflammation of the womb, and had suffered from a purulent vaginal discharge for the last ten years, with pain over the sacrum, and dragging pains down the thighs. I found a smooth, rounded swelling occupying the hypogastric region, resembling about a fifth-month pregnancy. There were no intermittent contractions, and no movements to be felt on palpation. I could not hear any foetal heart sounds, but there was a well-marked whizzing murmur heard all over the swelling, more distinctly over the left side. I found no marked vaginal changes or shortening or softening of the cervix uteri, and no abnormal bulging. I was unakle to recognise the fundus uteri on bimanual examination. The breasts were slightly swollen and tender and the veins conspicuous, the areolæ being also darker than usual and somewhat swollen. I told the patient that she was probably pregnant and arranged to see her again in a month. Battley's opium solution in fifteen-minim doses greatly relieved the abdominal pains, and had to be continued in increasing doses, as she said that she could not exist without it. Three weeks afterwards she called to tell me that she had felt the child's movements. She had improved in her general health and appearance. The bladder and bowels continued normal. I did not examine her again until November. The movements had then ceased for about a month, though they had been very strong. She had slight metrorrhagia during the latter half of September. The abdomen was greatly distended and the superficial veins dilated. There was now marked fluctuation, and the usual physical signs of encysted fluid. No muscular contraction of the cyst-wall; no sound on auscultation. The cervix was not perceptibly altered, and the uterus appeared to be fixed by perimetritic adhesions. I indistinctly felt what I believed to be the limbs of a fœtus on gently manipulating the tender abdomen.

On Jan. 26th, 1886, I asked a friend to see the case, and he thought it was an ovarian tumour, with no fotus inside or outside the uterus. I sent her next day to Dr. Frank C C 2 
Nicholson of Hull, who kindly examined the case. He also suspected that it was ovarian cystic disease, and suggested tapping at once, and removal by abdominal section in a month if it filled up again. On the 31 st she was admitted into the Grimsby Hospital. After using the catheter, I tapped her on Feb. 1st, and withdrew 101 ounces of dark, opaque, brownish-green coloured fluid, sp. gr. 1020. Microscopically it showed numerous leucocytes, granular débris, and large granular masses resembling the so-called granular ovarian cells described by Drysdale, and a few oil-globules. For the next fortnight she suffered from acute peritonitis, the temperature varying from $100^{\circ}$ to $103^{\circ} \mathrm{F}$, and was too ill to permit further examination. A severe attack of vomiting and diarrhœe followed, which was relieved by starch and opium injections. She rallied for a few days; the temperature became normal; but a slough now began to form through the abdominal walls a little below and to the right of the umbilicus, and she gradually sank and died on March 15 th.

Necropsy, six hours after death.-There was great emaciation and an absence of subcutaneous fat. About four ounces of fetid purulent fluid escaped on opening the abdominal cavity, and the tumour was found to consist of a full-term, well-developed male child, placed abdomino-anterior, breech downwards, and in an advanced state of decomposition. The placenta was detached, and mostly absorbed. The sac presented a black appearance, and had undergone secondary jnflammation and suppuration. The uterus was small, firmly tixed, quite empty, and its cavity measured two inches.

Remar\%s.-This case is interesting as showing the difficulty of diagnosis in such cases. Playfair says that "the diagnosis of abdominal gestation is by no means so easy as might be thought, and the most experienced practitioners have been mistaken with regard to it." Barnes, in his last work, says that "almost all the cases in which this form of gestation was suspected which have come under our observation turned out to be ovarian cysts."

\section{AN INTERESTING CASE OF GALL-STONES, WITH NECROPSY.}

\section{By ALBER T WILSON, M.D.}

THE following case is of interest at the present time, when abdominal surgery offers such relief to cases of obstructed gall-ducts.

Mrs. B-- aged sixty-five, first consulted me four years ago. She had for a long while experienced pain in the region of the gall-bladder, which had been treated as indigestion. On examination, I found below the tenth costal cartilage a large movable pear-shaped lump about three inches long, which could easily be grasped; it was the dilated gall-bladder. The stools being of normal colour, the obstruction would be in the cystic duct, and the hepatic and common ducts would be free. I treated her with large doses of belladonna, fomentations, and purging with podophyllin and colocynth. The result was that two gall-stones were passed (or rather found in the stools), also a large quantity of biliary gravel. The swelling and pain entirely disappeared, and therefore a cure seemed effected. The patient enjoyed good health for three years, when another similar but slighter attack came on, with distension of the gall-bladder, but it yielded to the same treatment. This time, though symptoms of stones were present, none were found, but much gravel was passed. Again, in January, 1886, she became ill. There was pain over the gall-bladder, which yielded to belladonna vomiting was also present, but it resisted all the medicines employed, and yielded only to pancreatised food. There were no symptoms of gall-stones, and the gall-bladder could not be felt. She recovered so far as to be able to get downstairs for a few days, but again became ill, and died on Jan. 29th. Her death was not connected with the liver disease. She was extremely weak, the vomiting had returned, and two days before death curious convulsive clonic spasms set in, which seemed to cause death by exhaustion. As the nervous symptoms form a rare and interesting case of themselves, I shall briefly narrate them, especially as the cause was obscure. On January 28 th, at 6 P.M., a fainting fit, with unconsciousness for a short period, ushered in the attack, although there had been occasionally throughout the day twitchings of the face and hands. After the faint the twitching set in all over the body: first an arm, then a leg, then the head, then the chest, would be jerked off the bed. On careful examination certain groups of muscles appeared to be affected; those at the back of the neck jerking the head back. The temporals, masseters, and sterno-mastoids, the muscles of the hyoid bone, jaw and tongue, were all in constant activity, tending to bite and jerk the thermometer out of the mouth, the deltoid and pectorals jerking the arm inwards. The biceps, the flexors, pronators, and opponent muscles of the thumb kept the hands and arms in constant motion. The flexors of the legs pointed the toes. Swallowing and speech were affected. She could only speak, and then with an effort, after the administration of amyl had relieved the spasms. Sensation and tendon reflex were diminished; ankle-clonus was absent; volitional power over the limbs was normal. She was quite conscious. The respiration and temperature were normal; the pulse was 140 . There was retention of urine in the early stage; later on, the urine and stools were passed involuntarily. On Jan. 29th, the clonic spasms continued, but were feebler, the muscles being exhausted; those of the jaw and neck were the most active. She died during the night. Only an examination of the abdomen was permitted, so that the seat of the nervous lesion must remain a matter of speculation.

Necropsy.-Abdomen: The stomach was empty. The mucous membrane, which was coated with dirty-brown slime, was very congested, and covered with minute pinpoint ecchymoses. Repeated attacks of peritonitis had matted together the duodenum with all the adjacent parts. What seemed to be the gall-bladder, but really proved to be an enormously dilated cystic duct, projected half an inch below the liver. I removed the whole mass, with part of the liver, for more thorough examination, and the result was very instructive. On opening the duodenum, the orifice of the common duct was easily found. It was dilated, and would easily admit my forefinger. Passing the finger up, I could feel bare gall-stones. On opening up the common duct, the hepatic duct was found normal in size. Passing to the cystic duct, 1 was amazed to find it dilated into one large cavity. This duct was dilated into a thin-walled carity, three inches long and two inches wide, and contained eight large gall-stones with smooth polished facets. On further dissection, a slightly thickened ring indicated the dilated orifice of the gall-bladder. The gall-bladder formed a smaller cavity than that of the cystic duct. Its walls were slightly thickened, and it only contained five stones, one of which was in a distinct pouch at the most distal part. The whole dissection revealed how completely disorganised these parts get when gall-stones accumulate; and it is of great interest that the presenting part, instead of being the gall-bladder, was the cystic duct-a fact worth remembering for cases of operation.

The treatment I employed was belladonna in large doses to relax muscular spasm, and purges to excite reflex contraction of the gall-bladder to expel the stones. Two or three stones and much gravel were passed after the different attacks. The treatment, however, was only partially successful, for although many stones had been expelled from the gall-bladder, for want of sufficient vis a tergo some were retained in the dilated cystic duct. By operation the stones could have been very easily removed, as they were all so loosely arranged. The gall-bladder, being provided with muscular fibres, must have a slight expulsive force, which is probably excited reflexly by purgation. This process can be aided by relaxing the neck of the bladder and cystic duct by belladonna, chloral, or opium. The cystic duct has no muscular fibres, while its mucous membrane has several folds ; it is, therefore, passive, and has no expulsive power, which accounts in this case for its great dilatation, and for the greater number of the gall-stones lying in it.

Leytonstone.

Foreign Medical Appointuents.-Dr. Kosturin, of St.Petersburg, has been appointed Extraordinary Professor of General Pathology in the University of Kharkoff. Dr. Hans Virchow is to succeed Dr Hofmann in the charge of the anatomical instruction in the Berlin Academy of Art. Dr. Joseph Schröter has qualified as privat docent in the University of Breslau, with the view of cultivating especially the science of Bacteriology. Dr. Friedrich Korányi, Clinical Professor in the University of Buda Pesth, has been appointed Rector for the ensuing academical year. 